\title{
SPATIAL PATTERN EVOLUTION AND DRIVING FACTORS OF PM 2.5 CONCENTRATIONS IN THE GRAND CANAL REGION FROM 2000 TO 2018
}

\author{
Xi Wang ${ }^{1}$, Miaole $\mathrm{Hou}^{1 *}$, Shisong $\mathrm{Cao}^{1}$, Bolun $\mathrm{Li}^{1}$ \\ ${ }^{1}$ School of Geomatics and Urban Spatial Informatics, Beijing University of Civil Engineering and Architecture, Beijing
}

KEY WORDS: $\mathrm{PM}_{2.5}$, Spatiotemporal Pattern, Spatial Autocorrelation, Trend Analysis, Geographical Weighted Regression (GWR), Driving Factors

\begin{abstract}
:
In recent years, air pollution related to $\mathrm{PM}_{2.5}$ has caused a significant impact on human health. The Grand Canal (GC) is not only a great Cultural heritage created in ancient China but also the longest and largest canal in the world. Based on remotely sensed $\mathrm{PM}_{2.5}$ gridded data in the GC region covering 2000 to 2018, we used the holistic methods of standard deviation ellipse, local moran index, slope trend analysis to reveal the spatiotemporal evolutions of $\mathrm{PM}_{2.5}$ concentrations in the $\mathrm{GC}$ regions and investigated the driving factors of $\mathrm{PM}_{2.5}$ concentrations by using the geographically weighted regression (GWR) model. Results show that (1) $\mathrm{PM}_{2.5}$ concentrations in the GC region exhibited an increasing trend and followed by a decreasing trend from 2000 to 2018 (the turning point emerged in 2010). (2) The standard deviation ellipse analyses show that the spatial distributions of $\mathrm{PM}_{2.5}$ concentrations featured more and more concentrated over time, whereas, after the year 2010, the distributions gradually featured scattered. (3) The concentrations of $\mathrm{PM}_{2.5}$ exhibited the strong effects of local spatial autocorrelation and areas with "high-high" agglomeration were mainly located in the central and west regions of the GC region and gradually expanded to the north over time. (4) The areas of regions with rapidly increasing in $\mathrm{PM}_{2.5}$ concentrations gradually decreased over time, however, those with rapidly decreasing in $\mathrm{PM}_{2.5}$ concentrations increased. (5) The influences of the natural factors and socio-economic factors on the distributions of $\mathrm{PM}_{2.5}$ concentrations varied spatially. In detail, the elevation was negatively correlated with $\mathrm{PM}_{2.5}$ concentrations, whereas an opposite relationship between industrial structure and $\mathrm{PM}_{2.5}$ concentrations was observed. The coefficients of rainfall, population density, GDP per capita and foreign investment show different results in positive and negative correlations depending on the position.
\end{abstract}

\section{INTRODUCTION}

Air pollution dominated by inhalable particles seriously affected people's physical and mental health. The "Plan for the Protection, Inheritance and Utilization of the Grand Canal Culture", released in 2019, stated that, accounted for less than $10 \%$ of China's land area, the eight provinces (cities) along with the GC, carry more than one-third of China's population and contribute nearly half of China's GDP in 2017. The provinces (cities) along the GC are one of the regions with the most developed economic and the strongest development momentum in China. Therefore, studying the temporal and spatial distribution of $\mathrm{PM}_{2.5}$ concentrations in the $\mathrm{GC}$ is of great significance for the health of one-third of the population in China, understanding the relationship between economic development and air pollution and formulating corresponding policies.

Scholars have conducted a series of studies on the spatiotemporal variation law of $\mathrm{PM}_{2.5}$. From the perspective of time span, air pollution studies in china mainly discussed the changing law of $\mathrm{PM}_{2.5}$ in different seasons, months, and days in a certain year, or the changing law of $\mathrm{PM}_{2.5}$ concentrations in some years over time ( $\mathrm{Li}$ et al., 2017). From the perspective of space, the study areas of most scholars are mainly concentrated in the Beijing-Tianjin-Hebei region, Pearl River Delta and Yangtze River Delta (Wu et al., 2020). There are few studies on the central and eastern plains, so it is urgent to strengthen the research on the spatiotemporal variation of $\mathrm{PM}_{2.5}$ concentrations over a long-time span in the central and eastern plains. To explore the source of air pollution, studies focus on exploration of $\mathrm{PM}_{2.5}$ concentrations driving factors. In order to quantitatively analyze the driving factors of $\mathrm{PM}_{2.5}$ concentrations, Scholars mainly start from two aspects: natural factors and social factors, natural factors including rainfall, topography, temperature, humidity, vegetation cover, wind speed, etc., and social factors including population density, per capita GDP, private cars holdings, industrial structure, foreign investment, etc. (Zhao et al., 2018). As for research methods, correlation analysis, generalized additive models (GAM), gray correlation model, geographic detector and spatial econometric model (Ding et al., 2019) were used to study the influencing factors of $\mathrm{PM}_{2.5}$.

The GC region includes not only the densely populated areas in the central and eastern regions, but also the developed coastal areas in the east. Therefore, it is very important to take the $\mathrm{GC}$ region as a typical case study. Based on the above discussion, the research objectives of this article are as follows:

(1) To explore the characteristics of the time-series change of $\mathrm{PM}_{2.5}$ concentrations in the GC region from 2000 to 2018 .

(2) To explore the spatial pattern evolution of $\mathrm{PM}_{2.5}$ concentrations in the GC region from 2000 to 2018.

(3) To explore the driving factors of $\mathrm{PM}_{2.5}$ concentrations change in the GC region in 2015. 


\section{STUDY AREA AND DATA}

\subsection{Study Area}

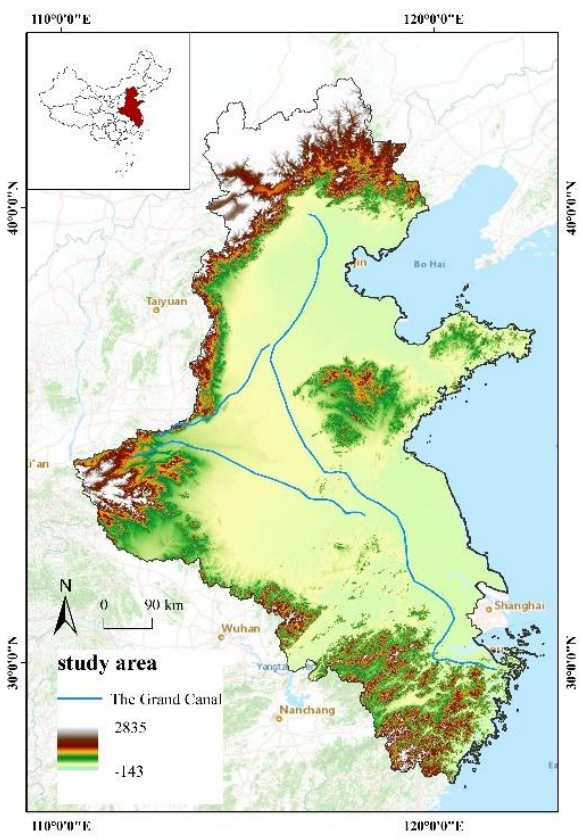

Figure 1. Study area

Figure 1 shows the geographical location of the GC. It is the longest artificial canal in the world, which is located in the central and eastern part of China and spans two municipalities (Beijing and Tianjin) and six provinces (Hebei, Shandong, Jiangsu, Zhejiang, Henan and Anhui). The eight provinces (cities) along the GC account for less than $10 \%$ of China's land area, carry more than one-third of China's population and contribute nearly half of China's GDP in 2017. It was excavated in the 5th century BC and in China's long history, it has always been a strategically important North and South material Transportation channels. At the same time, as the framework of the regional water system, it plays an important ecological service function, which is one of the main factors for the formation of many cities in this region. In 2014, the GC of China was successfully inscribed on the World Heritage List and has played an important role ever since.

\subsection{Data}

In this study, the average annual concentrations of $\mathrm{PM}_{2.5}$ is used to express the degree of air pollution. The annual concentrations of $\mathrm{PM}_{2.5}$ comes from the Organization for Atmospheric Composition Analysis (ACAG). The data is integrated with the data of remote sensing monitoring, model simulation and site measurement. The original data is $0.01 \times$ 0.01 grid data from 2000 to 2018, which has high accuracy and was widely used. Data from atmospheric composition analysis group (https://sites.wustl.edu/acag/). Natural factors and social factors include rainfall, elevation, population density, per capita GDP, industrial structure (ratio of secondary industry GDP to GDP) and foreign investment. Among them, rainfall and high range data come from the Center of Environmental Science and Data (https://www.resdc.cn/), social factors including population density, per capita GDP, industrial structure and foreign investment all come from the Yearbook of Chinese Urban Statistics.

\section{METHODOLOGY}

\subsection{Spatial Pattern Analysis}

3.1.1 Mean Center and Standard Deviation Ellipse: Standard deviation ellipse first put forward by Lefever in 1926, now it is mostly used to reveal the various characteristics of geographic elements from a global and spatial perspective. It is a spatial statistical method that reveals the spatial distribution and spatial evolution of geographic elements. It quantitatively describe the centrality, directionality, and other characteristics of the spatial distribution of elements through parameters such as spatial distribution range, center, long axis, short axis, and azimuth (Lefever, 1926). The mean center of $\mathrm{PM}_{2.5}$ concentrations can be calculated by the following formula:

$$
X_{t}=\frac{\sum_{i=1}^{n} x_{i} * P M_{2.5 i}}{n} ; Y_{t}=\frac{\sum_{i=1}^{n} y_{i} * P M_{2.5 i}}{n},
$$

where $\quad X_{t}, Y_{t}=$ the latitude and longitude of the centroid of $\mathrm{PM}_{2.5}$ concentrations in year $\mathrm{t}$ $x_{i}, y_{i}=$ the latitude and longitude of point $\mathrm{i}$; $\mathrm{PM}_{2.5 \mathrm{i}}=$ the $\mathrm{PM}_{2.5}$ concentrations of point $\mathrm{i}$ $\mathrm{n}=$ the number of $\mathrm{PM}_{2.5}$ concentrations points

3.1.2 Spatial Autocorrelation: Spatial autocorrelation is mainly used to study the potential interdependence among variables. Spatial autocorrelation is measured using global and local indicators. Local Moran 's I index was used to identify spatial agglomeration and spatial heterogeneity (Ye et al., 2018). The formula is as follows:

$$
I=\frac{n^{2} \sum_{i=1}^{n} \sum_{j=1}^{n} W_{i j}\left(x_{i}-\bar{x}\right)\left(x_{j}-\bar{x}\right)}{\left(\sum_{i=1}^{n}\left(x_{i}-\bar{x}\right)^{2}\right)^{2}},
$$

where $\quad x_{i}, y_{i}=$ the average annual concentrations of $\mathrm{PM}_{2.5}$ in unit $\mathrm{i}$ and $\mathrm{j}$

$\bar{x}=$ the average value of all units

$W_{i j}=$ the spatial weight matrix of unit $\mathrm{i}$ and $\mathrm{j}$

3.1.3 Trend Analysis: A linear slope analysis was used to determine the variation trend of $\mathrm{PM}_{2.5}$ concentrations in the $\mathrm{GC}$ region, the formula is as follows:

$$
\text { slope }=\frac{n * \sum_{i=1}^{n} i * P M_{2.5 i}-\left(\sum_{i=1}^{n} i\right)\left(\sum_{i=1}^{n} P M_{2.5 i}\right)}{n * \sum_{i=1}^{n} i^{2}-\left(\sum_{i=1}^{n} i\right)^{2}},
$$

where $\quad$ slope $=$ the trend in the $\mathrm{PM}_{2.5}$ concentrations $\mathrm{PM}_{2.5}=$ the grid unit $\mathrm{PM}_{2.5}$ concentration $\mathrm{n}=$ the time span $\mathrm{i}=$ the time unit

\subsection{Analysis of Driving Factors}

Geographically Weighted Regression (GWR) Model combines spatial correlation and linear regression to improve the traditional model and has certain advantages over traditional models such as the ordinary least squares (OLS). GWR is a local statistical method, which adds the spatial location of data into the regression parameters to effectively reflect the neglected local characteristics (Brunsdon et al., 1998). The model is defined as:

$$
y_{i}=\beta_{0}\left(u_{i}, v_{i}\right)+\sum_{k} \beta_{k}\left(u_{i}, v_{i}\right) x_{i k}+\varepsilon_{i},
$$

Where $\quad\left(u_{i}, v_{i}\right)=$ the central coordinate of position $\mathrm{i}$ 
$\beta_{k}\left(u_{i}, v_{i}\right)=$ the regression coefficient of the $\mathrm{k}$-th variable in position $\mathrm{i}$

$\beta_{0}\left(u_{i}, v_{i}\right)=$ the intercept of the model at position $\mathrm{i}$

$\varepsilon_{i}=$ the error of the model at position i

In this study, Gauss function method is selected as the weight function, which is expressed as follows:

$$
W_{i j}=\exp \left(-\left(\frac{d_{i j}}{b}\right)^{2}\right)
$$

Where $\quad W_{i j}=$ the weight between city $\mathrm{i}$ and $\mathrm{j}$

$\mathrm{b}=$ the bandwidth

$d_{i j}=$ the distance between city $\mathrm{i}$ and $\mathrm{j}$

\section{RESULTS}

\subsection{Time Series Variation Characteristics of $\mathbf{P M}_{2}$ Concentrations}

Figure 2 shows the variation of the average $\mathrm{PM}_{2.5}$ concentrations in the GC region from 2000 to 2018. The $\mathrm{PM}_{2.5}$ concentrations is divided into five categories using the Natural Breaks (Jenks) . As shown in Figure 2, The $\mathrm{PM}_{2.5}$ concentrations generally shows a trend of increasing first and then decreasing. From 2000 to 2010, $\mathrm{PM}_{2.5}$ concentrations showed an overall trend of increase and gradually decreased from 2010. The average concentrations of $\mathrm{PM}_{2.5}$ in the region was low in 2000 and the overall environmental quality was good, with the $\mathrm{PM}_{2.5}$ concentrations less than $76.16 \mu \mathrm{g} / \mathrm{m}^{3}$. From 2000 to 2010, the concentrations of $\mathrm{PM}_{2.5}$ over $76.16 \mu \mathrm{g} / \mathrm{m}^{3}$ has been increasing, mainly in central and southern Hebei Province, central and eastern Henan Province, western Shandong Province and northern Anhui Province and in most other regions. Since 2010, the environment in the GC region has gradually improved, the average $\mathrm{PM}_{2.5}$ concentrations has been decreasing. By 2018, the average $\mathrm{PM}_{2.5}$ concentrations in all provinces and cities except Shijiazhuang, Hebei Province, and Anyang, Henan Province had dropped below $76.16 \mu \mathrm{g} / \mathrm{m}^{3}$.
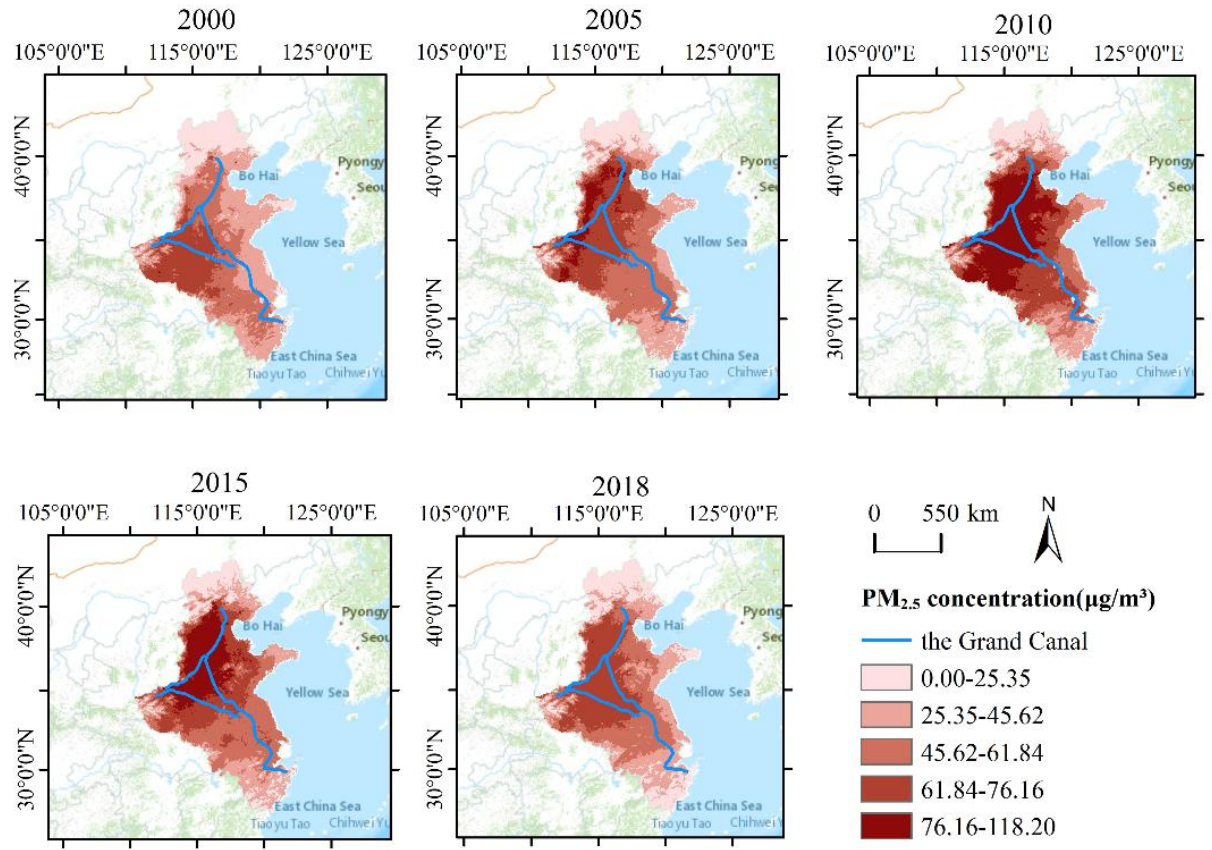

Figure 2. Temporal and spatial changes of $\mathrm{PM}_{2.5}$ concentrations in the $\mathrm{GC}$ region from 2000 to 2018 .

\subsection{Spatial Variation Characteristics of $\mathbf{P M}_{2.5}$ Concentrations}

4.2.1 Mean Center and Standard Deviation Ellipse: In order to explore the evolution characteristics of the temporal and spatial pattern of $\mathrm{PM}_{2.5}$ concentrations in the GC region, this study uses the standard deviation ellipse to quantitatively explain the centrality, ductility, directionality and spatial shape of the $\mathrm{PM}_{2.5}$ concentrations in the GC region.

Figure 3 shows the spatial variation of mean center and standard deviation ellipse of $\mathrm{PM}_{2.5}$ concentrations in the $\mathrm{GC}$ region from 2000 to 2018 . It can be seen from the figure 3:

(1) From the perspective of the coverage area of the ellipse, the area of the standard deviation ellipse first decreased from $67.93 \mathrm{~km}^{2}$ in 2000 to $65.12 \mathrm{~km}^{2}$ in 2010 , and then increased to $65.37 \mathrm{~km}^{2}$ in 2018 . It decreased from 2000 to 2010 and increased slowly from 2010 to 2018. This shows that the spatial distribution of $\mathrm{PM}_{2.5}$ concentrations is becoming more and more concentrated from 2000 to 2010 , and the spatial distribution of $\mathrm{PM}_{2.5}$ concentrations is gradually dispersed from 2010 to 2018.

(2) From the perspective of azimuth changes, $\mathrm{PM}_{2.5}$ concentrations in the $\mathrm{GC}$ region generally presents a "northwest - southeast" spatial distribution pattern, with the turn Angle increasing from $165.17^{\circ}$ in 2000 to $168.85^{\circ}$ in 2010 , and then slowly decreasing to $168.48^{\circ}$ in 2018 . It shows that the spatial distribution pattern of $\mathrm{PM}_{2.5}$ in the GC region shifts first to the direction of "North - South" and then slowly shifts to the direction of "East - West".

(3) From the perspective of the mean center, the center of 
gravity of the spatial distribution of $\mathrm{PM}_{2.5}$ concentrations in the $\mathrm{GC}$ region gradually shifted northward from 2000 to 2015, and shifted southward from 2015 to 2018 .

(4) There is a big difference between the length of the long axis and the short axis of the standard deviation ellipse, which also confirms that the spatial distribution of $\mathrm{PM}_{2.5}$ concentrations has obvious directivity. In the $\mathrm{GC}$ region, the ratio of long axis to short axis increased from 2000 to 2005 , decreased from 2005 to 2010 and then increased slowly from 2010 to 2018 .

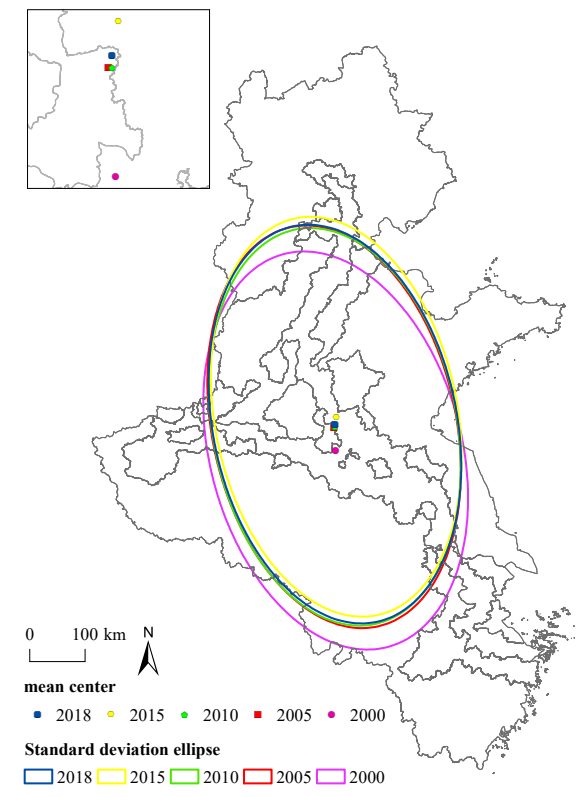

Figure 3. Spatial variation of mean center and standard deviation ellipse of $\mathrm{PM}_{2.5}$ concentrations in the $\mathrm{GC}$ region from 2000 to 2018 .

4.2.2 Local Spatial Autocorrelation: Figure 4 shows the results of local spatial autocorrelation of $\mathrm{PM}_{2.5}$ concentrations in the GC region from 2000 to 2018. The research units are divided into four types:

(1) The "high-high" correlation type (HH) refers to the spatially high concentrations of $\mathrm{PM}_{2.5}$. This type of $\mathrm{PM}_{2.5}$ concentrations has small spatial differentiation, showing a significant positive spatial correlation and the pollution in and around the area is relatively serious. It can be seen from the figure 4 that the high-value clusters between 2000 and 2018 were mainly concentrated in the central and southern part of Hebei, central and eastern part of Henan, western part of Shandong and northern part of Anhui. Moreover, the high-high agglomeration gradually expanded northward from 2000 to 2010 while the high-high agglomeration gradually expanded southward from 2015 to 2018.

(2) "Low-low" association type (LL) means that the $\mathrm{PM}_{2.5}$ concentrations is a low-value aggregation state in space. Low-low aggregation is mainly distributed in the south and north of the GC and a small part is distributed in the east. From 2000 to 2015, the low-low aggregation in the north and east gradually decreased while the low-low aggregation in the south gradually increased. From 2015 to 2018, the low-low aggregation increased in the north and east while the low-low aggregation decreased in the south.

(3) Other associations include "high-low" associations (high $\mathrm{PM}_{2.5}$ concentrations surrounded by low $\mathrm{PM}_{2.5}$ concentrations) and "low-high" associations (low $\mathrm{PM}_{2.5}$ concentrations surrounded by high $\mathrm{PM}_{2.5}$ concentrations). It can be seen from the figure 4 that only a small number of cities are distributed in "highlow" agglomeration areas. This result is credible because $\mathrm{PM}_{2.5}$ has strong spatial dispersion so that isolated high or low values are difficult to appear.
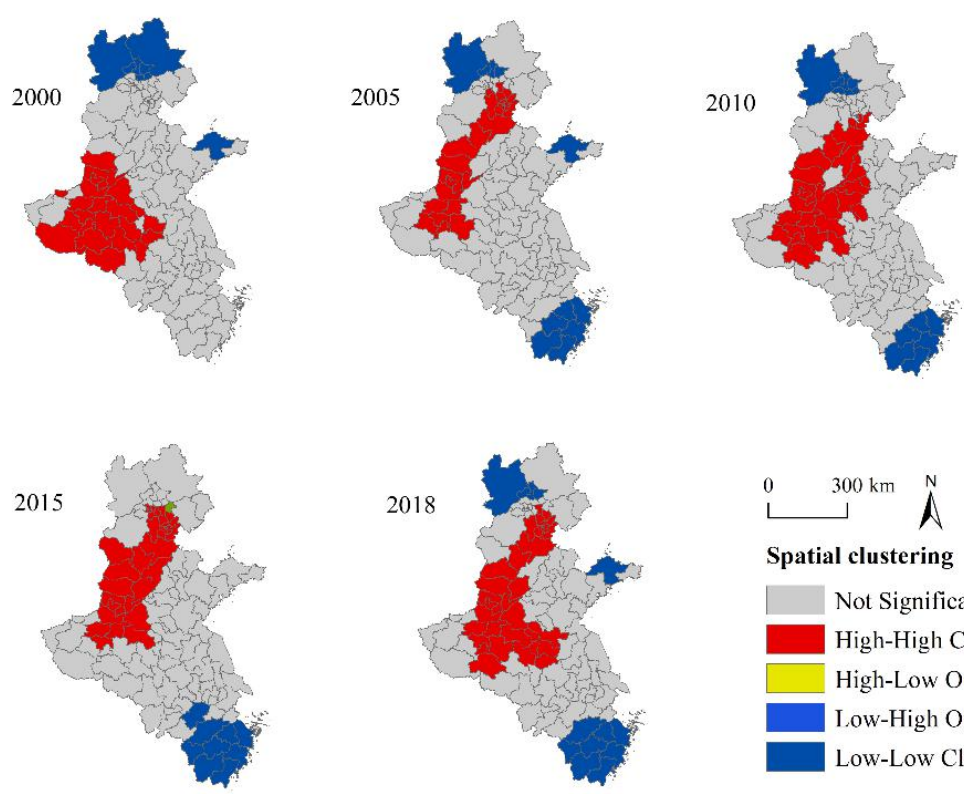

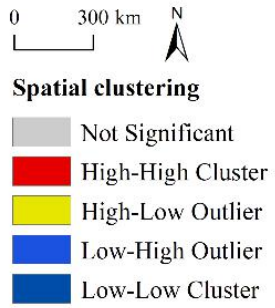

Figure 4. Local Moran Index of $\mathrm{PM}_{2.5}$ concentrations in the GC region from 2000 to 2018

4.2.3 Slope Trend Analysis: Figure 5 shows the spatial distribution of $\mathrm{PM}_{2.5}$ concentrations trends in the $\mathrm{GC}$ region from 2000 to 2018. It can be seen from the figure 5 that area with rapid growth of $\mathrm{PM}_{2.5}$ in the $\mathrm{GC}$ region gradually decreased while area with rapid reduction of $\mathrm{PM}_{2.5}$ gradually increased from 2000 to 2018. 

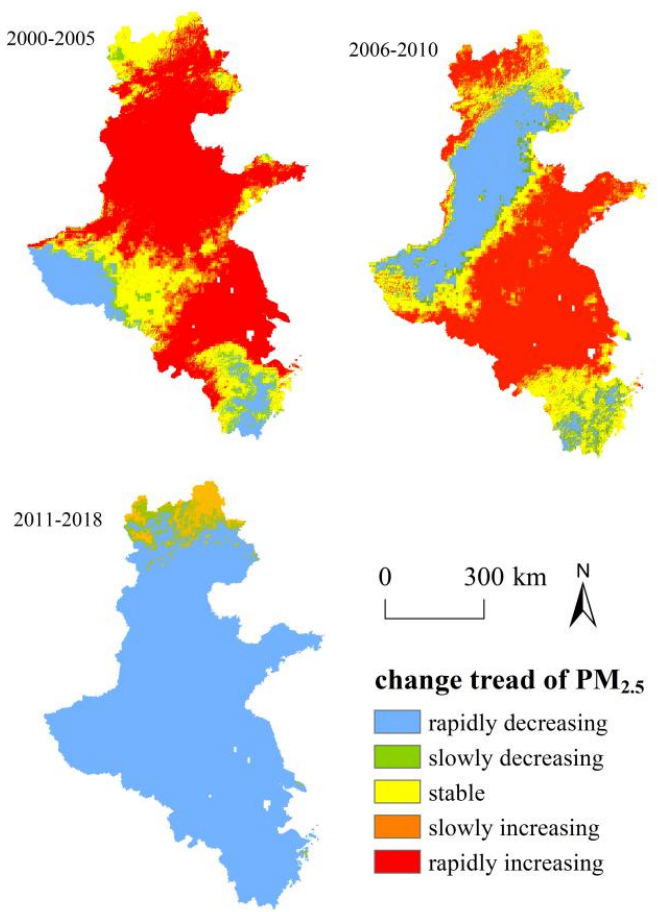

Figure 5. Change trend of $\mathrm{PM}_{2.5}$ in $\mathrm{GC}$ region from 2000 to 2018

(1) The ecology of the GC region deteriorated and $\mathrm{PM}_{2.5}$ increased sharply during 2000-2005. Rapidly decreasing, slowly decreasing, stable, slowly increasing and rapidly increasing accounted for $22.02 \%, 5.59 \%$, $19.79 \%, 7.76 \%$, and $44.53 \%$ respectively.

(2) From 2006 to 2010 , the area where $\mathrm{PM}_{2.5}$ increased rapidly in the $\mathrm{GC}$ region decreased while area where $\mathrm{PM}_{2.5}$ decreased rapidly increased. The area where the rapidly decrease was mainly concentrated in the middle of the GC region. Rapid decrease, slow decrease, stable, slow increase and rapid increase accounted for $22.02 \%$, $5.59 \%, 19.79 \%, 7.76 \%$, and $44.53 \%$ respectively.

(3) $\mathrm{PM}_{2.5}$ in the GC region decreased rapidly During 20112018. A few area in the north remain stable, no rapid increase area and a few area increase slowly. Rapid decrease, slow decrease, stable, slow increase, and rapid increase accounted for $93.20 \%, 3.53 \%, 3.28 \%$, $0.02 \%$, and $0.00 \%$ respectively.

\subsection{Spatial Heterogeneity Analysis of Influencing Factors}

In this study, the GWR model was used to explore the spatial difference of $\mathrm{PM}_{2.5}$ concentrations in 2015 under the influence of different factors. Influencing factors include rainfall, elevation, population density, per capita GDP, industrial structure (the ratio of gross domestic product of secondary industry to GDP) and foreign investment. Figure 6 shows the spatial distribution of the fitting degree $\mathrm{R}^{2}$ of the results of the geographically weighted regression model. It represents the degree of fit between the indicators selected by the GWR model and the actual $\mathrm{PM}_{2.5}$ concentration. The results show that the $\mathrm{R}^{2}$ distribution of all the prefecture-level cities ranges from 0.68 to 0.84 and all greater than 0.5 , which indicates that the indicators selected in this study have a strong explanatory power for $\mathrm{PM}_{2.5}$ concentrations.

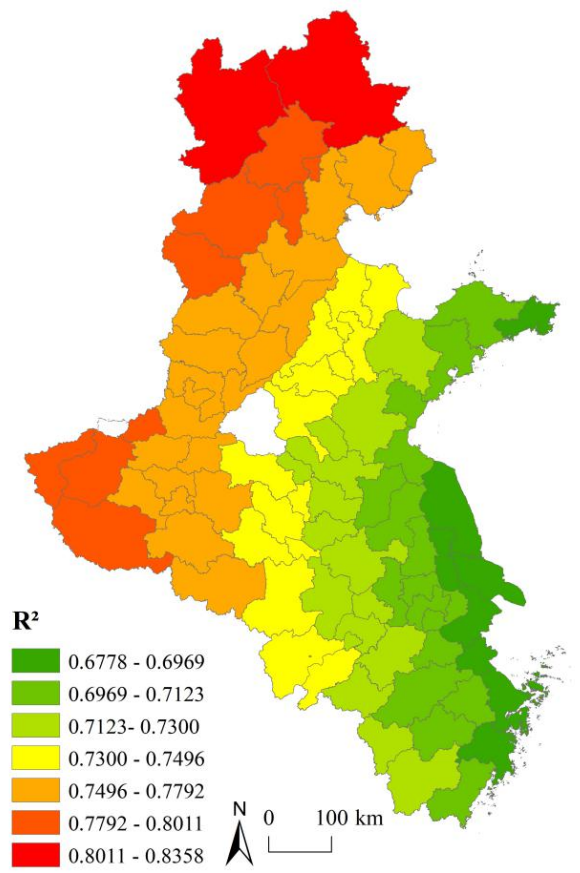

Figure 6. Spatial distribution of fitting degree $R^{2}$ of GWR model

Figure 7 shows the spatial distribution of regression coefficients of influencing factors in the GWR model. It can be seen from Figure 7 that precipitation, population density, per capita GDP and foreign investment show different correlations with different cities while the elevation has a negative correlation with $\mathrm{PM}_{2.5}$ and the industrial structure has a positive correlation with $\mathrm{PM}_{2.5}$. From the perspective of the absolute value of the coefficient, the order of the degree of influence of each factor from high to low is: elevation, precipitation, population density, industrial structure, foreign investment, per capita GDP. The specific analysis results are as follows:

Population density has a negative correlation effect on the $\mathrm{PM}_{2.5}$ concentrations in the southern area of the GC, accounting for $35.51 \%$ of the proportion of prefecture-level cities in the total area of the GC. Since the southern part of the GC is mostly economically developed coastal areas, population growth may promote the growth of science and technology, thereby changing the industrial structure: from high energy consumption, high pollution industries to low pollution, technology-based industries. This is why the population density and $\mathrm{PM}_{2.5}$ concentrations in the southern area of the GC are negatively correlated. For the central and northern areas of the $\mathrm{GC}$, population density has a positive correlation with $\mathrm{PM}_{2.5}$ concentrations and the positive correlation coefficient from south to north is getting larger, which means that with the increase of population density in the central and northern areas of the GC, the air pollution is getting more and more serious. This is because in the central and eastern plains, with the increase in population density, traffic flow has increased and pollution has become more serious.

The influence of per capita GDP on the $\mathrm{PM}_{2.5}$ concentrations in the GC region shows a trend of "Northeast-Southwest" changes. In the southwest of the GC region, per capita GDP and $\mathrm{PM}_{2.5}$ concentrations are positively correlated, accounting for $34.58 \%$ of the city in the $\mathrm{GC}$ region. It can be seen from Figure 7 that in the southwestern region of the GC, especially the central and western parts of Henan Province, 
with the increase of per capita GDP, the concentrations of $\mathrm{PM}_{2.5}$ has increased which indicating that the economic level of the region has increased at the expense of the environment. In the northeastern part of the GC, the per capita GDP and $\mathrm{PM}_{2.5}$ concentrations are negatively correlated which indicating that the region's economic growth does not rely on highly polluting industries.

The industrial structure of the $\mathrm{GC}$ region is mainly positively correlated with $\mathrm{PM}_{2.5}$ concentrations, which also confirms that industrial production is the main cause of air pollution. From the southwest to the northeast of the GC region, the coefficient gradually increases, which indicating that the industrial structure of the northeast region of the $\mathrm{GC}$ region has a stronger correlation with $\mathrm{PM}_{2.5}$ concentrations than the southwest region.

The proportion of prefecture-level cities with negative correlation between foreign investment and $\mathrm{PM}_{2.5}$ concentrations accounted for $81.31 \%$, indicating that as the amount of foreign investment increases in most regions, the $\mathrm{PM}_{2.5}$ concentrations will gradually decrease. Among them, the areas where foreign investment and $\mathrm{PM}_{2.5}$ concentrations are negatively correlated are mainly concentrated in the central and northern parts of the GC while a small part of the southern area shows a positive correlation, indicating that foreign investment in the southern coastal areas has increased air pollution.

The influence of rainfall on $\mathrm{PM}_{2.5}$ presents a stepwise change from west to east. Rainfall has a negative correlation with the $\mathrm{PM}_{2.5}$ concentrations in the western and central regions of the GC and a positive correlation with the $\mathrm{PM}_{2.5}$ concentrations in the eastern region of the GC and the closer to the east coast, the stronger the positive correlation. The positive correlation is mainly distributed in the eastern coastal area of the GC while in the central and western parts of the $\mathrm{GC}$, the impact of rainfall on $\mathrm{PM}_{2.5}$ is negatively correlated. That is, in Hebei, Beijing, Henan, western Shandong and Anhui, abundant Rainfall can improve $\mathrm{PM}_{2.5}$ concentrations.

Elevation is negatively correlated with $\mathrm{PM}_{2.5}$ concentrations in the entire GC region, indicating that as the elevation increases, the $\mathrm{PM}_{2.5}$ concentrations tends to decrease. The regions with the strongest negative correlations are located in Hebei, the western part of Henan Province, and the southern part of Zhejiang Province. The region with the weakest negative correlation is located in the northernmost part of the GC region, that is, northern Hebei Province.

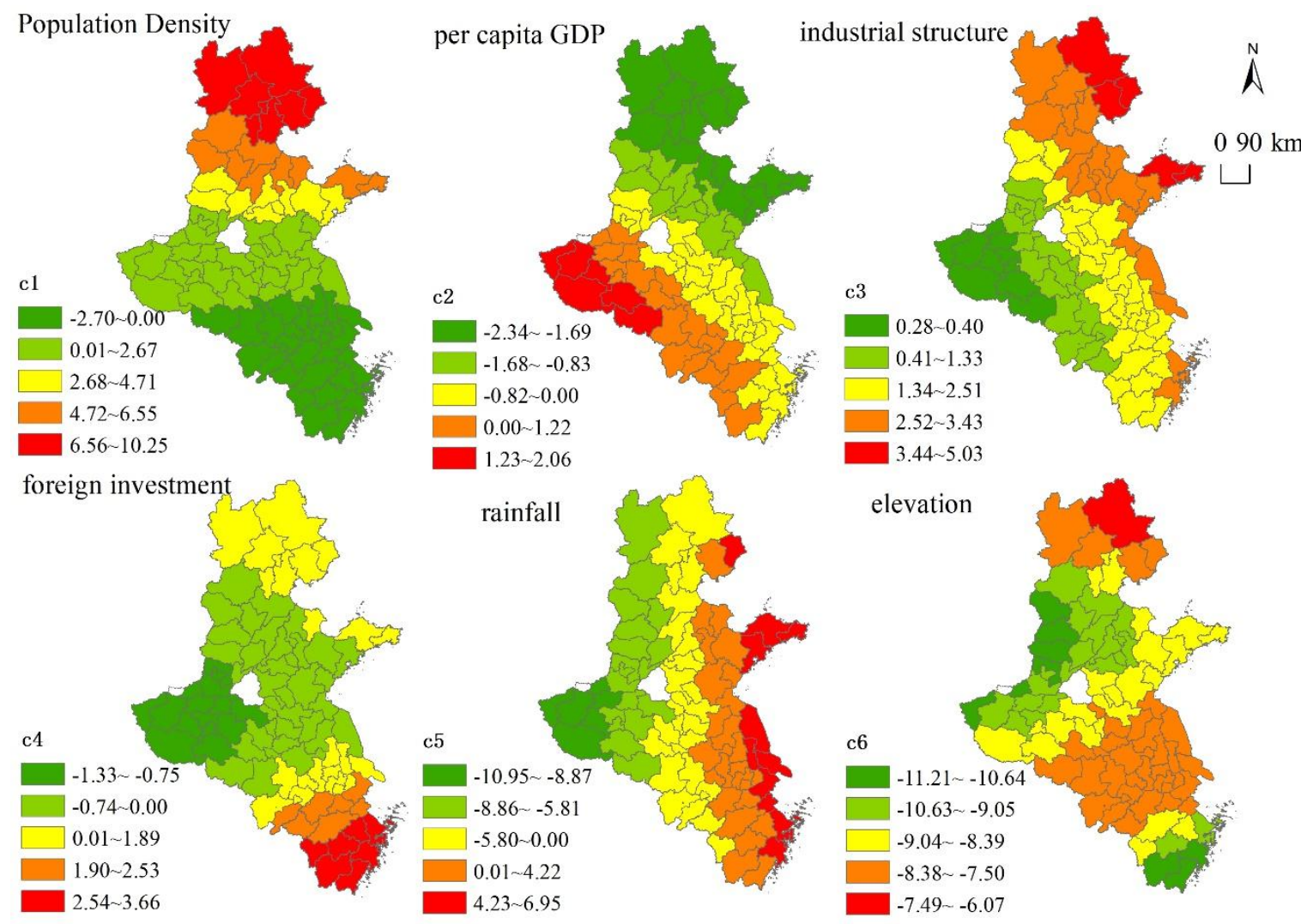

Figure 7. Spatial distribution of regression coefficients of influencing factors in the GWR model.

\section{DISCUSSION}

In this paper, the spatial pattern evolution and driving factors of $\mathrm{PM}_{2.5}$ concentrations in $\mathrm{GC}$ region were studied for the first time. This paper uses three spatial analysis methods: mean center and standard deviation ellipse, spatial autocorrelation, and trend analysis to explore the spatial distribution of $\mathrm{PM}_{2.5}$ in the region and obtain the result that the $\mathrm{PM}_{2.5}$ concentrations center in the GC region from 2000 to 2018 shifted northward and then southward. Through spatial autocorrelation, we know that $\mathrm{PM}_{2.5}$ "high-high" accumulation in the $\mathrm{GC}$ region is mainly distributed in the western and central parts of the region, namely Henan and Hebei. Through trend analysis, it is found that the $\mathrm{PM}_{2.5}$ 
concentrations in most regions increased rapidly from 2000 to 2005 , and the $\mathrm{PM}_{2.5}$ concentrations in most regions decreased rapidly from 2011 to 2018.For the research on the driving factors of $\mathrm{PM}_{2.5}$ concentrations in the $\mathrm{GC}$ region, it is concluded that the driving effect of each influencing factor on the $\mathrm{PM}_{2.5}$ concentrations in the $\mathrm{GC}$ region is spatially heterogeneous. Therefore, for the management of $\mathrm{PM}_{2.5}$ in different regions, it is necessary to 1 adapt measures to local conditions and propose different treatment measures according to the size of the driving factor coefficients of each region.

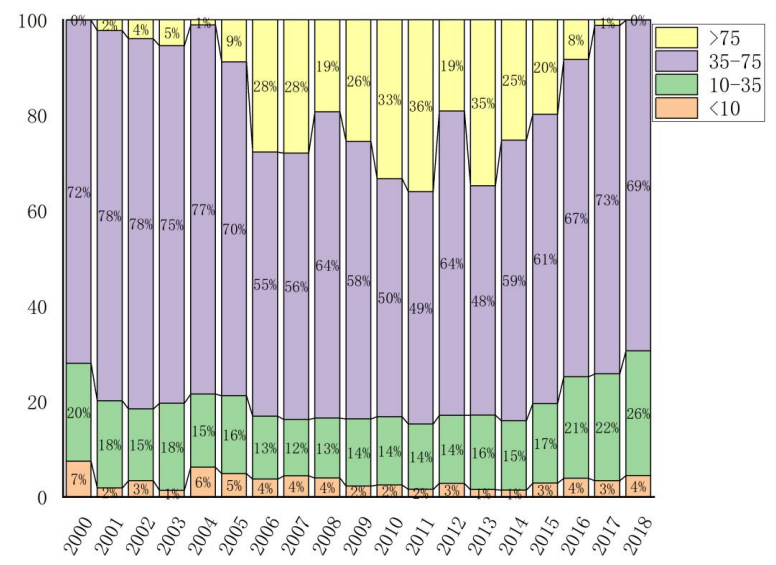

Figure 8. Area change of $\mathrm{PM}_{2.5}$ concentrations in $\mathrm{GC}$ from 2000 to 2018

Studies have shown that the increase of $\mathrm{PM}_{2.5}$ concentrations not only leads to the decrease of atmospheric visibility but also increases the incidence and mortality of cardiovascular diseases, respiratory diseases and lung cancer, bringing serious risks to human health(Xing et al. 2016). The Ministry of Environmental Protection officially listed $\mathrm{PM}_{2.5}$ as an important monitoring index in the "Environmental Air Quality Standard" (GB3095-2012) issued by the Ministry of Environmental Protection and set the $\mathrm{PM}_{2.5}$ concentrations standard according to the domestic economic development and air pollution status, among which the first-level standard is the 24-hour average concentrations no more than $35 \mu \mathrm{g} / \mathrm{m}^{3}$ and the second-level standard is no more than $75 \mu \mathrm{g} / \mathrm{m}^{3}$ (Chow 1995). According to this standard, $\mathrm{PM}_{2.5}$ annual average mass concentrations values in the GC region from 2000 to 2018 were divided into 4 sections (Figure 8 ) and the area proportions of different sections were analyzed. The results showed:

(1) only in 2000 and 2018 , there was no area where the concentrations of $\mathrm{PM}_{2.5}$ was greater than $75 \mu \mathrm{g} / \mathrm{m}^{3}$.

(2) Taking the annual average $\mathrm{PM}_{2.5}$ concentrations limit of $35 \mu \mathrm{g} / \mathrm{m}^{3}$ proposed by China's Ambient Air Quality Standard (GB3095-2012) as the measurement standard, the average annual $\mathrm{PM}_{2.5}$ concentrations above $35 \mu \mathrm{g} / \mathrm{m}^{3}$ in the nine years from 2006 to 2014 accounted for a large proportion (over $83 \%$ ), indicating a high pollution level in most areas of the GC in recent years.

(3) In 2010, 2011 and 2013, more than 30\% of areas with $\mathrm{PM}_{2.5}$ concentrations greater than $75 \mu \mathrm{g} / \mathrm{m}^{3}$ accounted for $33 \%, 36 \%$ and $35 \%$ of the total area, respectively, further indicating the high pollution in these three years.

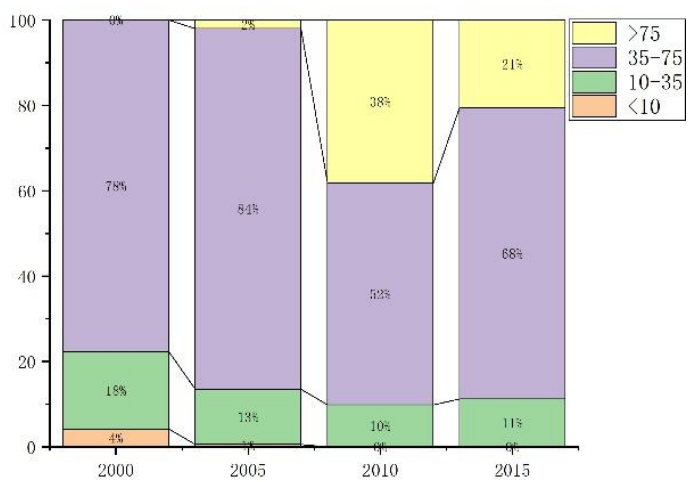

Figure 9. The proportion of population exposure in different $\mathrm{PM}_{2.5}$ concentrations intervals in the $\mathrm{GC}$ region

According to the above four intervals divided by the annual average concentrations of $\mathrm{PM}_{2.5}$ in the $\mathrm{GC}$ region, every five years is a unit, the proportion of population exposure in different intervals in each year is calculated (Figure 9). It can be discovered:

(1) Only $4 \%$ of the population in 2000 and $1 \%$ in 2005 were exposed to $\mathrm{PM}_{2.5}$ concentrations below $10 \mu \mathrm{g} / \mathrm{m}^{3}$ and only in 2000 did not exist populations exposed to $\mathrm{PM}_{2.5}$ concentrations above $75 \mu \mathrm{g} / \mathrm{m}^{3}$.

(2) In these years, $78 \%, 86 \%, 90 \%$ and $89 \%$ of the population were exposed above the $\mathrm{PM}_{2.5}$ mass concentrations limit $\left(35 \mu \mathrm{g} / \mathrm{m}^{3}\right)$, which indicating that the air quality in the region where most of the population lived was not optimistic.

(3) Based on the regional area variation chart of $\mathrm{PM}_{2.5}$ concentrations in the GC region from 2000 to 2018, it can be seen that the population is mainly concentrated in areas above the annual average $\mathrm{PM}_{2.5}$ concentrations limit of $35 \mu \mathrm{g} / \mathrm{m}^{3}$, resulting in a prominent high-density population in the GC region concentrated in areas with high pollution.

\section{CONCLUSION}

Through time series analysis, it is found that the $\mathrm{PM}_{2.5}$ in the $\mathrm{GC}$ region generally increased first and then decreased from 2000 to 2018. From 2000 to 2010, the $\mathrm{PM}_{2.5}$ generally showed an increasing trend and gradually decreased from 2010. Since 2010, the environment in the GC region has gradually improved and the average $\mathrm{PM}_{2.5}$ concentrations has been declining. By 2018, except for Shijiazhuang City in Hebei Province and Anyang City in Henan Province, the average $\mathrm{PM}_{2.5}$ concentrations in other provinces and cities has fallen to below $76.16 \mu \mathrm{g} / \mathrm{m}^{3}$. Analyze the reasons, the pollution concentrations of $\mathrm{PM}_{2.5}$ is closely related to the population density and the density of economic activities in geographical space. This is closely related to the inclusion of the construction of ecological civilization in the overall layout of the cause of socialism with Chinese characteristics in the 18th National Congress of China and the Air Pollution Prevention and Control Action Plan issued by the State Council in 2013. For Shijiazhuang City and Anyang City, $\mathrm{PM}_{2.5}$ remains high because the two cities have relatively developed steel industries.

There are obvious regional differences in the spatial distribution of $\mathrm{PM}_{2.5}$ concentrations in the $\mathrm{GC}$, mainly in 
central and southern Hebei Province, central and eastern Henan Province, western Shandong Province, and northern Anhui Province. The length of the long axis and the short axis of the standard deviation ellipse is quite different, which also confirms that the spatial distribution of $\mathrm{PM}_{2.5}$ concentrations has obvious directionality. From the perspective of changing trends, the areas where $\mathrm{PM}_{2.5}$ rapidly increased in the GC region gradually decreased from 2000 to 2018, and the areas where $\mathrm{PM}_{2.5}$ decreased rapidly increased gradually.

For the driving factors of $\mathrm{PM}_{2.5}$ concentrations, this article uses Geographically weighted regression model to carry out research. From the perspective of the absolute value of the coefficient, the degree of influence of each factor from high to low is: elevation, precipitation, population density, industrial structure, foreign investment and per capita GDP. The influence of various factors on the $\mathrm{PM}_{2.5}$ concentrations in the GC region shows obvious spatial heterogeneity. Among them, the influence of elevation on $\mathrm{PM}_{2.5}$ is negatively correlated, and the influence of industrial structure on $\mathrm{PM}_{2.5}$ is positively correlated. The coefficients of rainfall, population density, GDP per capita and foreign investment show different results in positive and negative correlations depending on the city. Therefore, it is necessary to consider the spatial heterogeneity of various factors when conducting $\mathrm{PM}_{2.5}$ governance, and propose different governance strategies for the specific conditions of different regions.

\section{ACKNOWLEDGMENTS}

We would first like to thank the anonymous reviewers for their valuable feedback. We appreciate the support of the Young Beijing Scholars Program

\section{REFERENCES}

Brunsdon, C., Fotheringham, S., Charlton, M., 1998: Geographically weighted regression. Journal of the Royal Statistical Society: Series D (The Statistician) 47, 431-443.

Ding, Y., Zhang, M., Qian, X., Li, C., Chen, S., Wang, W, 2019: Using the geographical detector technique to explore the impact of socioeconomic factors on PM2. 5 concentrations in China. Journal of cleaner production 211,1480-1490.

Lefever, D.W., 1926: Measuring geographic concentrations by means of the standard deviational ellipse. American journal of sociology 32,88-94.

Li, X., Chen, X., Yuan, X., Zeng, G., León, T., Liang, J., Chen, G., Yuan, X., 2017: Characteristics of particulate pollution (PM2. 5 and PM10) and their spacescaledependent relationships with meteorological elements in China. Sustainability 9(12), 2330.

Wu, W., Zhang, M., Ding, Y., 2020: Exploring the effect of economic and environment factors on $\mathrm{PM}_{2.5}$ concentrations: a case study of the Beijing-Tianjin-Hebei region. Journal of Environmental Management 268, 110703.

Ye, W.F., Ma, Z.-Y., Ha, X.Z., 2018: Spatial-temporal patterns of PM2. 5 concentrations for 338 Chinese cities.
Science of The Total Environment 631, 524-533.

Zhao, H., Guo, S., Zhao, H., 2018: Characterizing the influences of economic development, energy consumption, urbanization, industrialization, and vehicles amount on PM2. 5 concentrations of China. Sustainability 10, 2574. 